\title{
Highly Efficient EV Battery Charger Using Fractional Charging Concept with SiC
} Devices

Kanstad, Tore; Lillholm, Morten Birkerod; Zhang, Zhe

Published in:

Proceedings of 34th annual IEEE Applied Power Electronics Conference and Exposition

Link to article, DOI:

10.1109/APEC.2019.8722191

Publication date:

2019

Document Version

Peer reviewed version

Link back to DTU Orbit

Citation (APA):

Kanstad, T., Lillholm, M. B., \& Zhang, Z. (2019). Highly Efficient EV Battery Charger Using Fractional Charging Concept with SiC Devices. In Proceedings of 34th annual IEEE Applied Power Electronics Conference and Exposition IEEE. https://doi.org/10.1109/APEC.2019.8722191

\section{General rights}

Copyright and moral rights for the publications made accessible in the public portal are retained by the authors and/or other copyright owners and it is a condition of accessing publications that users recognise and abide by the legal requirements associated with these rights.

- Users may download and print one copy of any publication from the public portal for the purpose of private study or research.

- You may not further distribute the material or use it for any profit-making activity or commercial gain

- You may freely distribute the URL identifying the publication in the public portal 


\title{
Highly Efficient EV Battery Charger Using Fractional Charging Concept with SiC Devices
}

\author{
Tore Kanstad, Morten Birkerod Lillholm and Zhe Zhang \\ Department of Electrical Engineering \\ Technical University of Denmark (DTU) \\ Kgs. Lyngby Denmark \\ s144021@student.dtu.dk,s144006@student.dtu.dk,zz@elektro.dtu.dk
}

\begin{abstract}
This paper describes the implementation of the fractional power conversion concept for use in an on-board charger for Electric Vehicles (EV). High gain step up topologies are required and an efficiency analysis of the full bridge boost converter is made. A comparison of many power devices including $\mathrm{Si}$, GAN and $\mathrm{SiC}$ devices concludes that $\mathrm{SiC}$ devices are well suited for this application. Using loss equations and battery charging characteristics the converter is optimized for low loss in a full battery charge cycle. Switching-average methods model the small signal characteristics and a PI controller is implemented. The fractional charging configuration results in a very high current gain. A $100 \mathrm{kHz}$ prototype was tested on a $300 \mathrm{~V}$ EV battery, achieving a converter efficiency of $\mathbf{9 7 . 6 \%}$. For a $400 \mathrm{~V}$ battery the charger can charge $4 \mathrm{~kW}$ at more than $\mathbf{9 8 \%}$ efficiency. The power density of the charger is $3.6 \mathrm{~kW} / \mathrm{L}$.
\end{abstract}

Index Terms-Battery chargers, DC-DC power converters, Control system analysis, Control theory, Design optimization

\section{INTRODUCTION}

The number of electric vehicles (EVs) in the world is rapidly increasing, due to their environmental advantages, increasing attractiveness and governmental initiatives. However, electric vehicles still have several challenges such as limited range, high cost, slow charging and limited charging opportunities in cities. Increasing the EV battery charger efficiency and decreasing the size can help increase the charging rate and reduce the cost. This can boost the transition to electric cars and has become a hot research topic.

Several converters with comparable specifications to the one in this paper is found in existing literature. [1] lists a few relevant converter prototypes: [2] [3] [4] [5] [6], while some other are discussed in: [7] and [8]. These converters all have peak efficiencies in the range from $96 \%$ to slightly below $98 \%$.

In the fractional charger concept, the power flowing into the converter is only a fraction of the power flowing into the battery (Fig. 2). This is different to the conventional configuration where all the power flows through the converter as seen in Fig. 1.

The principle of fractional charging is not new [9], but is getting increased attention. Previous published research have documented the benefits of this configuration, i.e. the efficiency improvement and reduction of power that flows through converter [10] [11] [12].

The charger presented here take advantage of the fractional charging concept and proposes it as a solution for on-board EV

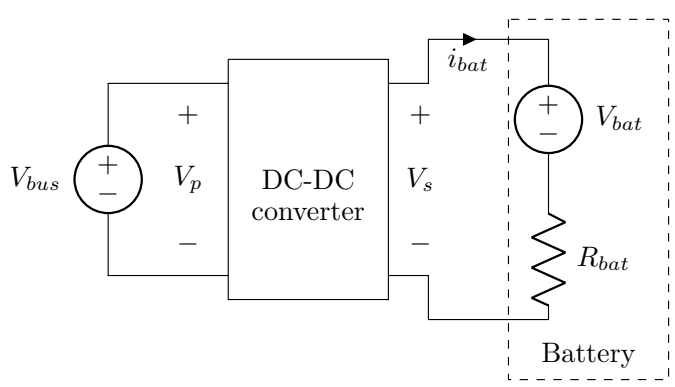

Fig. 1. Conventional Charging Configuration

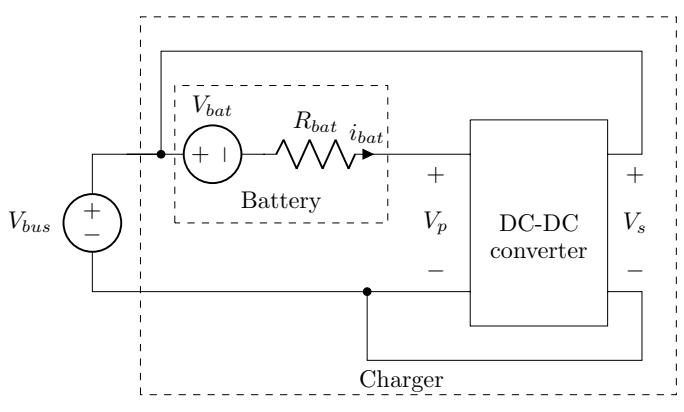

Fig. 2. Fractional Charging Configuration

chargers. It is both highly efficient, and allows for the DC/DC converter itself to have a lower power rating than the battery charging power. This makes it possible to use a smaller and cheaper converter, and to reduce the amount of power loss and heat generation.

\section{System DESCRIPTION}

The specifications of the charger is given in Tab. I. This implemented prototype is designed to be able to charge the battery pack of a Tesla Model $S$ and from a DC bus with the voltages that come from rectified 3-phase EU mains. The prototype is designed to have a smaller power rating than most other onboard chargers as this simplifies testing in the laboratory. 
TABLE I

CHARGER SPECIFICATIONS

\begin{tabular}{lll}
\hline \hline \multicolumn{1}{c}{ Symbol } & \multicolumn{1}{c}{ Parameter } & Rated Value \\
\hline$V_{\text {bus }}$ & DC-bus voltage & {$[489 \mathrm{~V}, 566 \mathrm{~V}]$} \\
$V_{\text {bat }}$ & Battery voltage & {$[288 \mathrm{~V}, 403 \mathrm{~V}]$} \\
$i_{\text {bat }}$ & Battery current & $10 \mathrm{~A}$ \\
$P_{\text {battery }}$ & Battery charging power & $4.0 \mathrm{~kW}$ \\
$P_{\text {converter }}$ & Converter power & $2.8 \mathrm{~kW}$ \\
$\Delta i_{\text {bat }}$ & Peak-to-peak ripple & $1.0 \mathrm{~A}$ \\
\hline
\end{tabular}

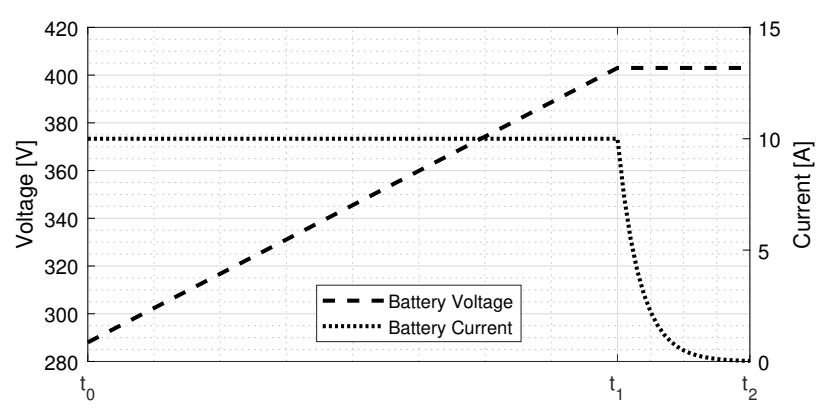

Fig. 3. Battery current and voltage during charging

\section{A. Fractional Battery charging}

The conventional charging configuration in Fig. 1 has the battery in parallel with the converter. This means that all the power that is used to charge the battery has to pass through the power converter and $V_{s}=V_{b a t}$. In the fractional concept in Fig. 2, the battery is placed in series with the converter. This makes it possible to charge with a lower converter input voltage, $V_{p}<V_{b a t}$, while maintaining the desired battery current and voltage, resulting in a lower power flow through the converter than the battery. This assumes that the battery voltage is lower than the bus voltage, $V_{b a t}<V_{b u s}$. Also, the battery voltage should be larger than half the bus voltage $V_{\text {bat }}>\frac{1}{2} V_{\text {bus }}$ for this configuration to be advantageous. Otherwise, the converter power will be higher than the battery charging power, which is inefficient.

The battery charging profile has constant current for most of the charging and constant voltage with a decaying current in the end of the charging cycle, shown in Fig. 3. The converter is assumed as a current source for design and testing purposes as this is how most of the energy will be charged to the battery.

\section{B. Efficiency Improvement}

As mentioned, the power flowing into the converter primary side, $P_{\text {converter }}$, is only a fraction of the power flowing into the battery, $P_{\text {battery }}$. This relation is given in (1) and the efficiency improvement compared to a conventional charger is given by (2). Here $\eta_{\text {charger }}$ is the efficiency of the entire charger system, while $\eta_{\text {converter }}$ is the efficiency of the DC-DC converter. These equations show that the fractional charging configuration is most feasible compared to the conventional configuration when the $k$ in (2) is low. This happens when the battery voltage is slightly lower than the bus voltage. If the bus voltage is much greater than the battery voltage, the advantage of this configuration diminishes.

$$
\begin{gathered}
k=\frac{P_{\text {converter }}}{P_{\text {battery }}}=\frac{V_{\text {bus }}-V_{\text {bat }}-R_{\text {bat }} i_{\text {bat }}}{V_{\text {bat }}+R_{\text {bat }} i_{\text {bat }}} \approx \frac{V_{b u s}-V_{b a t}}{V_{b a t}} \\
\eta_{\text {charger }}=\frac{1}{1+k \cdot\left(1-\eta_{\text {converter }}\right)}
\end{gathered}
$$

\section{Power Density Improvement}

According to (1) the power rating for a DC/DC converter used in the fractional concept can be much lower than that of a conventional configuration with the same charging power. This means that smaller converters can be designed, improving the power density of the system significantly.

\section{Topology and Voltage - Current Relationships}

The battery current $i_{b a t}$ is what needs to be controlled, and this is achieved by adjusting the duty cycle of the converter. As seen in Fig. 2 the secondary side voltage of the converter is fixed to the bus voltage, $V_{s}=V_{\text {bus }}$. Thus, the volt-second balance in the converter makes the primary side voltage, $V_{p}$, change as a function of the duty cycle. The change in $V_{p}$ causes a change in the voltage across the battery, which changes the battery current. A positive change in duty cycle decreases $V_{p}$ which increases the battery charging current $i_{\text {bat }}$. Furthermore, the current drawn from the DC bus will be lower than the charging current, as some current is fed back from the converter.

An important difference to the conventional configuration is that a step-up rather than a step-down converter is needed as the voltage at the primary side of the converter will be lower than the secondary side. Another difference is that the primary and secondary side will not be isolated as the two ground leads are connected. Nevertheless, isolated converter topologies such as Dual Active Bridge (DAB) and Full-Bridge Boost (FBB) were considered as they can achieve high efficiency at high voltage gains. The FBB in Fig. 4 was selected as it has been proven to achieve a high efficiency at very high voltage gains [13], and as the topology have an primary side inductor which makes it easy to control the battery current. Also, the hardswitching control scheme is simple and lends itself to a very broad efficient operating range .

The relationship between the secondary side and primary side voltage in a FBB is given by (3), where $n=\frac{n_{s}}{n_{p}}$ is the transformer turns ratio and $d$ is the inductor duty cycle. $\mathrm{Eg}$. the ratio of time where the inductor current increases to the inductor current period. The primary side and battery voltages can be found from this relationship combined with KVL in Fig. 2. $V_{p}=V_{b u s} \frac{1-d}{n}$ and $V_{b a t}+i_{b a t} R_{b a t}=V_{b u s}\left(1-\frac{1-d}{d}\right)$, 


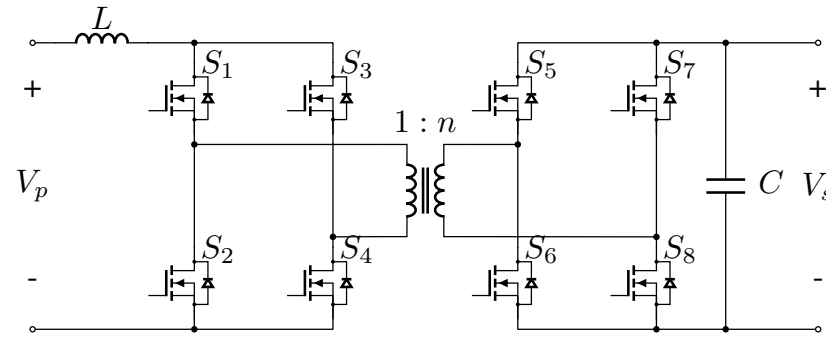

Fig. 4. FBB converter with synchronous rectification

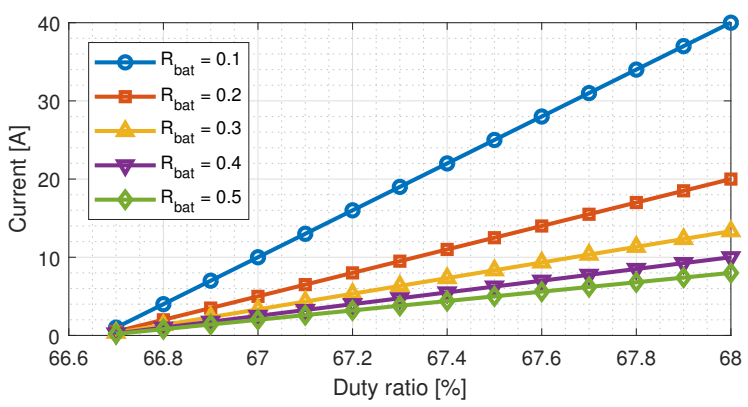

Fig. 5. The resulting steady-state current for small variations in duty cycle with five different battery series resistance values. $n=\frac{10}{6}, V_{b a t}=400$, $V_{\text {bus }}=500$

with the assumption that $R_{b a t}$ is the dominant resistance in series with the battery current. This leads to the expression for the battery current given in (4). This expression is extremely sensitive to variations in duty cycle. If the actual duty cycle of the converter deviates slightly from the theoretical one, the steady-state battery current will be much different than anticipated. Fig. 5 illustrates the current sensitivity to duty cyle with different equivalent series resistances, $R_{b a t}$.

$$
\begin{gathered}
\frac{V_{s}}{V_{p}}=\frac{n}{1-d} \\
i_{\text {bat }}=\frac{V_{\text {bus }}\left(1-\frac{1-d}{n}\right)-V_{b a t}}{R_{\text {bat }}}
\end{gathered}
$$

\section{DeSign CONSIDERATIONS}

For design purposes, the FBB converter must operate as a current source which makes it undesirable to have large capacitors at the primary side. This, and the fact that the secondary side is connected to the bus makes it possible with few capacitors. Furthermore, as the battery voltage $V_{b a t}$ approaches the bus voltage $V_{b u s}$, the voltage gain $\frac{V_{s}}{V_{p}}$ approaches infinity. This means that potentially very large voltage gains are required, and that there is an upper limit to the ratio $\frac{V_{b a t}}{V_{b u s}}$.

Efficiency, rather than power density was the priority during the design phase. First, an optimization was done in the transistor selection. Afterwards, the ideal switching frequency was estimated in order to minimize the energy loss for an entire charging cycle. The power loss formulas used are given in Tab. II.
TABLE II

EQUATIONS FOR ESTIMATION OF POWER LOSS

\begin{tabular}{ll}
\hline \hline \multicolumn{1}{c}{ Description } & \multicolumn{1}{c}{ Expression } \\
\hline Primary side conduction loss & $4 I_{p r m s}^{2} R_{D S O N}$ \\
Primary side switch loss & $2 f_{s w}\left(Q_{g} V_{G S}+W_{o s s}+\right.$ \\
& $\left(i_{b a t}-\frac{\Delta i}{2}\right) \frac{V_{s}}{n} t_{r i s e}+$ \\
& $\left.\left(i_{b a t}+\frac{\Delta i}{2}\right) \frac{V_{s}}{n} t_{f a l l}\right)$ \\
Secondary side conduction loss & $4 I_{s r m s}^{2} R_{D S}$ ON \\
Secondary side switch loss & $\approx 0($ Active rectification $)$ \\
Inductor conduction loss & $I_{b a t ~}^{2}{ }^{2} R_{L} D C+I_{b a t}^{2} A C^{2} R_{L} A C$ \\
Inductor core loss & $\approx 0(\mathrm{DC}$ current $\gg \mathrm{AC}$ current $)$ \\
Primary side winding loss & $I_{T p r m s}^{2} R_{p}$ \\
Secondary side winding loss & $I_{T s r m s}^{2} R_{s}$ \\
Transformer core loss (iGSE [14]) & $\frac{1}{T} \int_{0}^{T} k_{i}\left|\frac{d B}{d t}\right|^{\alpha}\left(\Delta B^{\beta-\alpha}\right) d t$, \\
& $k_{i}=\frac{k}{(2 \pi)^{\alpha-1} \int_{0}^{2 \pi}|\cos (\theta)|^{\alpha \cdot 2^{\beta-\alpha} d \theta}}$ \\
\hline
\end{tabular}

\section{A. Transformer Turns Ratio}

According to Tab I, the maximum DC-bus voltage $V_{\text {bus }}$ is $566 \mathrm{~V}$. At the lowest battery voltage $V_{b a t}=288 \mathrm{~V}$, the maximum converter input voltage is found as (5), resulting in a minimum converter voltage gain $\frac{V_{s}}{V_{p}} \approx 2$. The maximal gain is found in the same manner at the lowest bus voltage with the highest battery voltage, giving $\frac{V_{s}}{V_{p}} \approx 6$.

$$
V_{p, \text { max }}=V_{b u s, \text { max }}-V_{b a t, \text { min }}=566 \mathrm{~V}-288 \mathrm{~V}=278 \mathrm{~V}
$$

As the minimum gain of the FBB converter in equal to the transformer turns ratio $n$, the turns ratio must be slightly less than 2, to comply with the minimal gain constraint. The turns ratio $\frac{10}{6}=1.67$ satisfies this and is practical for implementation.

\section{B. Selecting FETS}

Both $\mathrm{Si}, \mathrm{SiC}$ and $\mathrm{GaN}$ field effect transistors (FETs) were considered, and a junction temperature of $70^{\circ} \mathrm{C}$ was assumed. The primary side FETs are expected to have the greatest power loss as this side has higher currents and as the secondary side is a rectifier with close to zero voltage switching. This is because the secondary switches are turned on shortly after their body diodes starts conducting. Thus, the selection of primary FETs is more critical than the selection of secondary FETs. The result from this optimization is shown in Fig. 6, and show that UnitedSiC's UJC506505K SiC cascode has the lowest losses for switching frequencies below $\approx 200 \mathrm{kHz}$, while GaN System's GS66508 is better at higher frequencies. The UJC506505K SiC is selected. Another advantage with this $\mathrm{SiC}$ cascode is that it can be driven by a normal MOSFET gate driver. This FET was also selected for the secondary side FETs as it proved to have fast body diode behaviour and high $\frac{d V}{d t}$ capability during tests. Actually the body diode outperformed external anti-parallel SiC diodes (Rohm SCS304AP). The switching frequency, $f_{s w}$, is here defined as the frequency 
TABLE III

DESIGN SUMMARY

\begin{tabular}{ll}
\hline \hline Part / Parameter & \multicolumn{1}{c}{ Details } \\
\hline Inductor & Foil wound, $400 \mu \mathrm{H}$ \\
Inductor Core & Ferroxcube ER51, 3C92 \\
FETs & $8 \times \mathrm{UJC} 06505 \mathrm{~K}$ \\
$f_{s w}$ & $100 \mathrm{kHz}$ \\
Transformer & Wire wound \\
Transformer Core & $2 \times$ Ferroxcube E58, 3C95 \\
Turns ratio $n$ & $\frac{10}{6}$ \\
Box Volume & $1.1 \mathrm{~L}$ \\
\hline \hline
\end{tabular}

of each switch. In a Full-Bridge Boost converter, the frequency of the inductor current will be twice of this, i.e. $2 f_{s w}$.

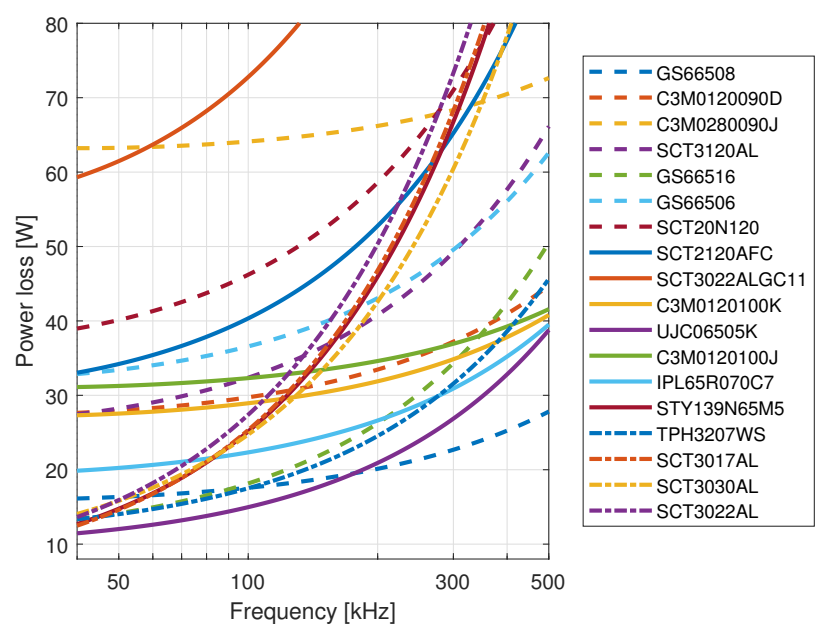

Fig. 6. Estimated primary side FET loss vs. frequency for different FETs

\section{Optimizing for Charging Profile and Switching Frequency}

When a preliminary design has been made, it is possible to look at how the changing battery voltage during charging affects the converter operation with regards to losses. As the battery voltage increases, the converter will operate with decreasing input voltage. A method for optimizing with regards to both battery charging and frequency is proposed here.

For any steady-state operating point, the converter losses can be estimated using the equations shown in Tab. II. This results in the loss function $P_{l o s s}\left(f_{s w}, V_{b a t}\right)$, which depends on the switching frequency $f_{s w}$ and the battery voltage $V_{b a t}$ and is a sum of the losses at a specific operating point. The function $P_{\text {loss }}\left(f_{s w}, V_{\text {bat }}\right)$ is shown for different battery voltages in Fig. 8. Integrating this function from the minimum battery voltage $V_{b a t, \min }$ to the maximum battery voltage $V_{b a t, \max }$ with respect to $V_{b a t}$ yields a number which can be described as the sum of losses across the entire operating range, or

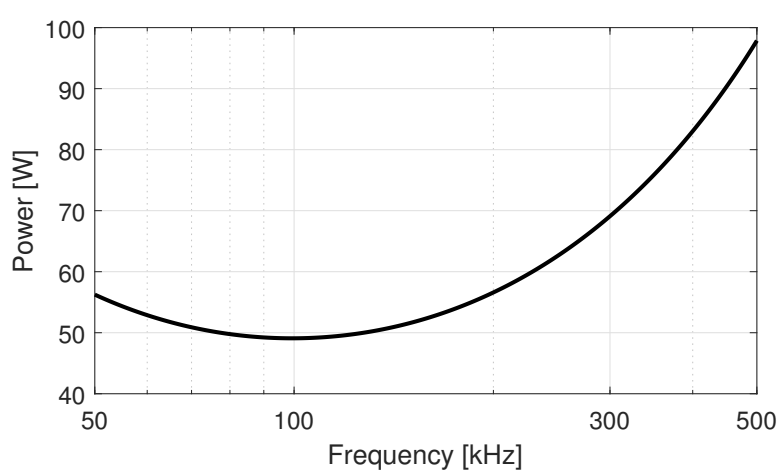

Fig. 7. Calculated average power loss vs. switching frequency during a full battery charging cycle

battery charging cycle. When done numerically, this number becomes very large, depending on how many operating points are included. This makes it useful to divide by the voltage interval between the minimum and maximum battery voltage. The result is a number which can be described as the average power loss across all operating points, or across the entire battery charging cycle. This number eases comparison between different designs, so the the optimal can be found. The mathematical description of this function is in (6). This method assumes that the battery voltage increases linearly with time as the battery is charged.

Because the expressions are frequency dependent, it is possible to sweep across relevant switching frequencies to determine the optimal switching frequency for a specific converter design. For the final design, with a constant battery current of $i_{b a t}=10 \mathrm{~A}$ and battery voltages $V_{b a t, \text { min }}=288 \mathrm{~V}$ $V_{\text {bat }, \max }=403 \mathrm{~V}$, the estimated average loss versus frequency from (6) is shown in Fig. 7. As shown, the converter is optimized for a switching frequency of $100 \mathrm{kHz}$.

$$
P_{\text {loss }, \text { cycle }}\left(f_{s w}\right)=\frac{\int_{V_{b a t, \text { min }}}^{V_{\text {bat } \text { max }}} P_{\text {loss }}\left(f_{\text {sw }}, V_{b a t}\right) d V_{b a t}}{V_{b a t, \text { max }}-V_{b a t, \text { min }}}
$$

The design choices are summarized in Tab. III.

\section{Modelling And CONTROL}

As seen in Fig. 2 the battery is represented by the Rint model although it does not take the capacitive and inductive effects of batteries into account [15]. This, combined with the fact that any secondary side capacitance will have its independence cancelled by the connection to the bus, makes the model of the charger system a first order one. A small signal model is made in order to design a controller. This model is derived by waveform averaging of the full-bridge boost as done in [16]. Here, the expressions describing the voltage across the inductor gives the differential equation (7).

$$
\begin{gathered}
L \frac{d i_{b a t}}{d t}=\left(V_{b u s}-V_{b a t}-R_{b a t} i_{b a t}\right) d+ \\
\left(V_{b u s}-V_{b a t}-R_{b a t} i_{b a t}-\frac{V_{b u s}}{n}\right)(1-d)
\end{gathered}
$$




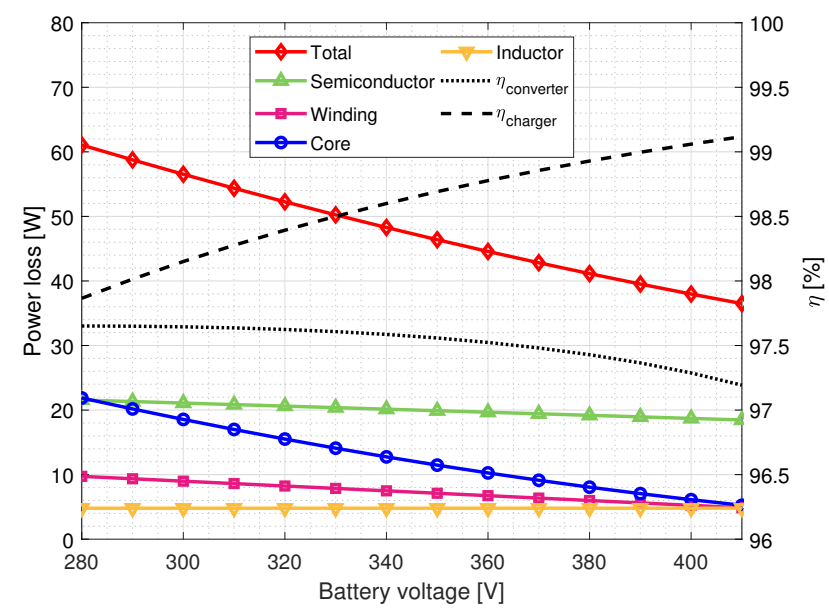

Fig. 8. Estimated power losses for the battery voltages seen during a full charging cycle, $f_{s w}=100 \mathrm{kHz}$

A perturbation is added to the duty cycle such that $d=D+\hat{d}$ and the response in battery current will be $i_{b a t}=I_{b a t}+\hat{i}_{b a t}$. By removing the DC terms, this equation is used to create a transfer function $G_{i d}$ which relates a duty cycle change to a battery current change (8). It should be noted that this is an approximation which does not include parasitic capacitance and inductance in battery, converter and wires. Furthermore, internal resistances in the converter are here neglected as they are assumed lower than the battery series resistance. Inclusion of these resistances would add an operating point dependent resistance in Fig. 9, which would decrease the DC gain and move the pole of the system to a higher frequency.

$$
G_{i d}(s)=\frac{\hat{i}_{\text {bat }}(s)}{\hat{d}(s)}=\frac{V_{\text {bus }}}{n} \frac{1}{s L+R_{b a t}}
$$

(8) can also be represented as an $\mathrm{AC}$ equivalent circuit as seen in Fig. 9.

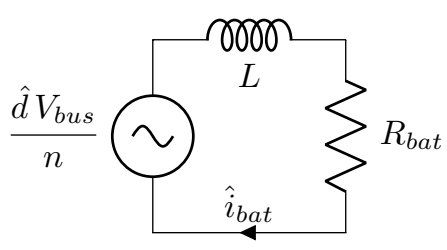

Fig. 9. Small signal model of charger (perturbation in duty cycle to change in battery current)

\section{A. Current Control in Fractional Charging}

Som new challenges are specific to the fractional concept, especially the high current gain. As the bus voltage normally is fairly high compared to the battery series resistance, the DC gain of this system will be high, which requires high PWM resolution. If the digital PWM resolution is insufficient, the smallest possible duty cycle change results in a current step of several amperes. Because of this, a high PWM resolution is required to reduce oscillations with the current going between the two nearest current levels.

In this work, a first order PI controller was successfully implemented on a Texas Instruments TMS320f28335 microcontroller unit.

\section{EXPERIMENTAL RESUlTS}

The implemented converter prototype is shown in Fig. 10.

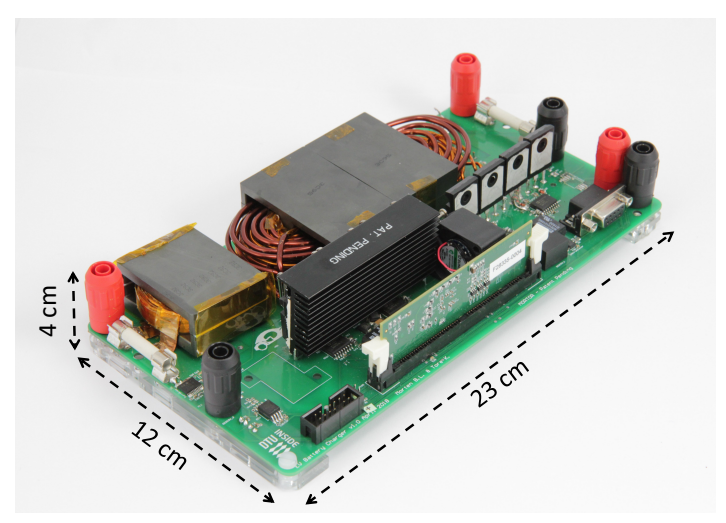

Fig. 10. The converter prototype

\section{A. Efficiency Measurements}

Several different variants of the DC-DC converter were tested in a conventional configuration with a resistive load to begin with. Designs with wire wound transformer and planar PCB transformer windings were compared. Different switching frequencies and types or rectification in the secondary side were also tested. These results are shown in Fig. 11, where the blue series mark the final design. The transformer with the PCB windings have low leakage inductance, but caused large switching losses as the terminal capacitance is high. The most efficient design was actually the one with $f_{s w}=75 \mathrm{kHz}$, but this resulted in high transformer losses and overheating.

With the final design, a peak efficiency of $\eta_{\text {converter }}=$ $97.6 \%$ is achieved at a converter input power of $1.63 \mathrm{~kW}$. And the efficiency stay above $97 \%$ for powers between $400 \mathrm{~W}$ and $2.8 \mathrm{~kW}$.

The converter is placed in the fractional charging concept (Fig. 2), and new efficiency measurements are performed while charging an electric vehicle. As stated by (1) and (2), the efficiency improvement due to this configuration depends on the bus and battery voltages. Fig. 12 and 13 show the efficiency measurements for the same battery voltage, but different DCbus voltages. In Fig. 12 the converter efficiency is almost as high as the charger efficiency because the $k$ factor is close to 1 . This shows only a modest improvement with the fractional configuration. In Fig. 13 the charger efficiency is markedly higher than the converter efficiency, as the $k$ factor is much lower than 1 . This shows a clear improvement with the fractional configuration, even as the converter itself actually 


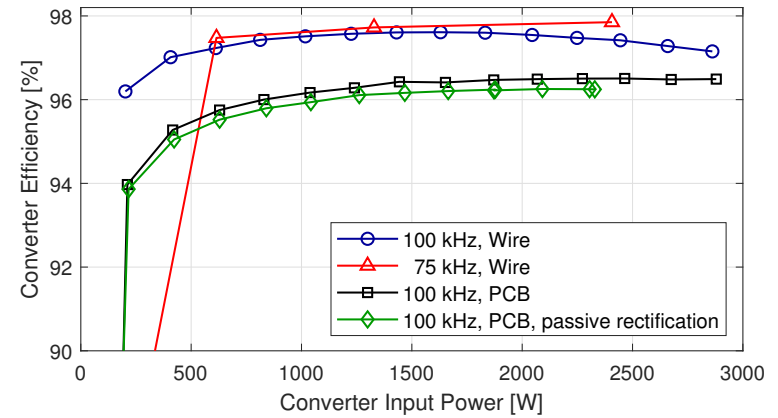

Fig. 11. Converter Efficiency vs. Input Power for different switching frequencies and transformers

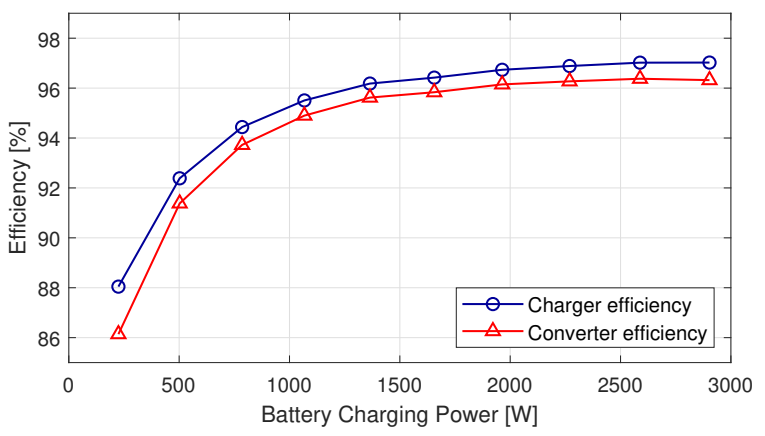

Fig. 12. Converter and charger efficiency vs. battery charging power. $V_{b a t}=$ $273 \mathrm{~V}, V_{\text {bus }}=540 \mathrm{~V}, k=0.9$

shows lower efficiency compared to Fig. 12. This is because the converter is operating with a higher gain, further away from its most efficient operating point. This shows that the highest efficiencies will be achieved if the converter itself has a high efficiency at high voltage gains.

\section{B. Converter Waveforms}

The most important converter waveforms are shown in Fig. 14 , where the converter is in the fractional configuration and charging with $10 \mathrm{~A}$ and $3.01 \mathrm{~kW}$. There is seen some ringing on the drain-source voltage for the primary side switches, but a

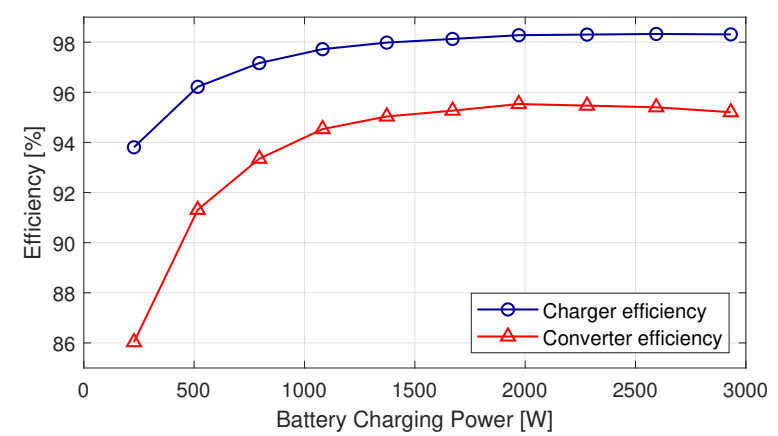

Fig. 13. Converter and charger efficiency vs. battery charging power. $V_{b a t}=$ $273 \mathrm{~V}, V_{\text {bus }}=400 \mathrm{~V}, k=0.4$

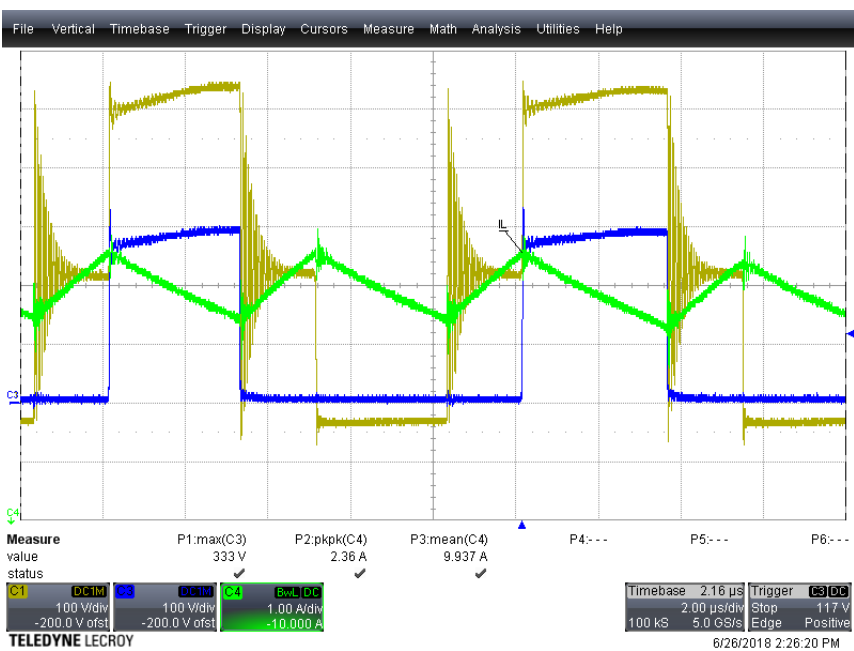

Fig. 14. Converter waveforms. $\square: i_{\text {bat }}(1 \mathrm{~A} /$ div $)$, $\mathbf{\square}: V_{D S_{S_{2}}}(100 \mathrm{~V} /$ div $)$, च: $V_{D S_{S_{8}}}(100 \mathrm{~V} /$ div $)$, Bandwidth $=150 \mathrm{MHz}$

lot more at the secondary side. This MHz-ringing is due to the leakage inductance and causes high losses in the transformer windings.

\section{Loss Distribution}

Accurately measuring loss distribution can be challenging in power electronics. For this project the loss distribution is estimated using a combination of electrical measurements, thermal measurements and calculated estimates. Firstly, a thermal model of the FETs with mounted heatsink is made, similar to [17], as shown in Fig. 15. This is done by controlling a constant DC current trough the devices and measuring the electrical power and the temperature rise on the shared heat sink with a thermal camera. This gives the thermal resistance $R_{t h, p r i F E T}$ of the 4 primary side FETs plus heat sink. The same procedure was used for the secondary side, but without the heat sink, resulting in $R_{t h, s e c F E T}$. The switching loss $P_{s w}$ is the difference between the conduction losses $P_{\text {cond }}$ and the total loss $P_{\text {total }}$, found as (9) and (10) from the heatsink temperature $T_{H S}$.

$$
\begin{gathered}
P_{s w}=P_{\text {total }}-P_{\text {cond }} \\
P_{\text {total }}=\frac{T_{H S}-T_{A}}{R_{t h}}, \quad P_{\text {cond }}=I_{r m s}^{2} \cdot R_{o n}
\end{gathered}
$$

For the secondary side FETs, used for synchronous rectification (SR), the swithing loss is not measured seperately. Inductor losses were estimated based on the measured resistance up to $1 \mathrm{MHz}, 5$ times the inductor current frequency of $200 \mathrm{kHz}$, measured with an impedance analyzer. Using a spectrum of the current up to the $1 \mathrm{MHz}$ this gives the inductor loss. This accounts mostly for the copper losses as the core losses can not be measured using small signals. Transformer core losses are estimated using the improved Generalized Steimetz Equation (iGSE) found in Tab. II. Control power for the microcontroller and gate drive is measured from a power 


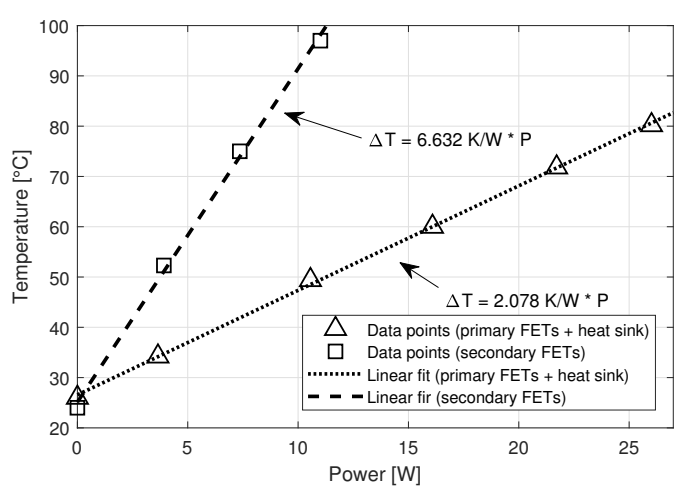

Fig. 15. Temperature versus dissipated power in the FET power devices of the converter and the linear fit used to find the thermal resistance

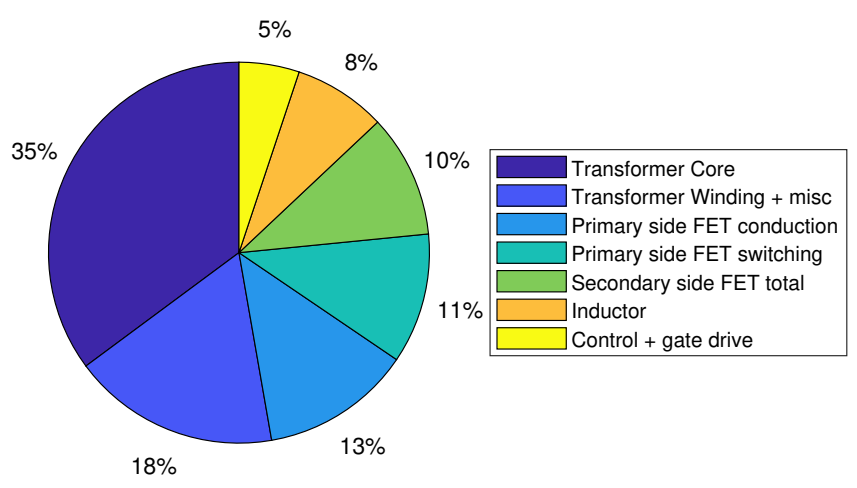

Fig. 16. Measured loss distribution for converter operating at $2.4 \mathrm{~kW}$ power, 10 A charging current. Total loss $=60 \mathrm{~W}$

supply. The remaining power is assumed to be mostly copper loss in the transformer windings and various trace losses in the PCB. The resulting loss distribution is shown in Fig. 16. Transformer core loss and winding loss contribute to about half of the total loss. The winding losses are slightly higher than the estimate, which can be caused by high frequency oscillations in transformer current, which would have high losses due to proximity and skin effect.

\section{Charging Current Steps}

Fig. 17 shows a step in the battery charging current with a rise time of $t_{r} \approx 0.6 \mathrm{~ms}$. Here the resistance in wires and battery were measured to $R_{b a t}=0.46 \Omega$. Currents steps were also performed with added resistances to investigate the effect on the system dynamics. The tests were done with total resistances of $R_{b a t}=0.99 \Omega$ and $R_{b a t}=2.16 \Omega$, and yielded rise times of $t_{r} \approx 0.8 \mathrm{~ms}$ and $t_{r} \approx 1.2 \mathrm{~ms}$ respectively. This verifies that the system response is slowed down by $R_{b a t}$ as expected from the AC analysis. However, the system response is overall slower than expected, which might be caused by battery capacitances and inductances which are not modelled.

There are some oscillations in $i_{b a t}$ at $20 \mathrm{kHz}$ which corresponds to the control bandwidth. This might be due to the duty cycle resolution of the micro-controller, where the smallest

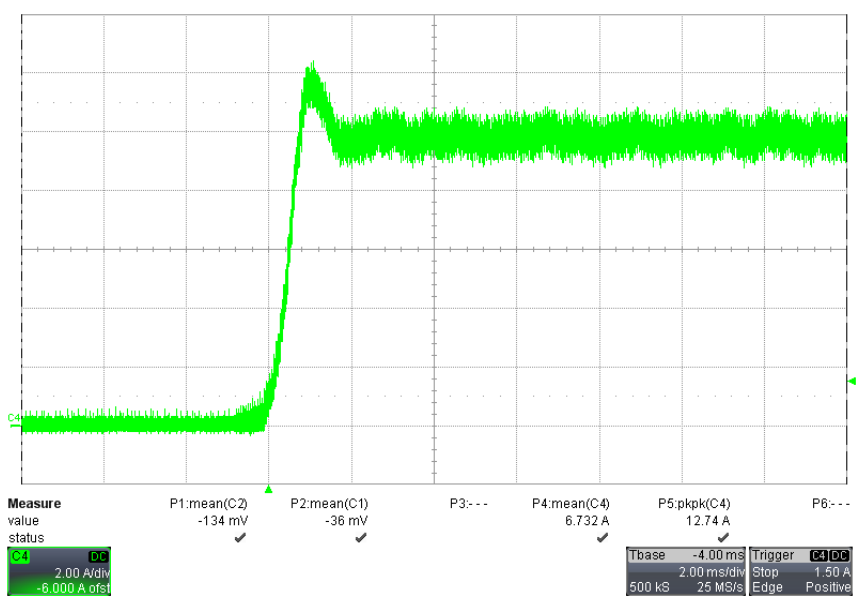

Fig. 17. 0 to $10 \mathrm{~A}$ battery current step for $V_{b u s}=540$ volt and $V_{b a t}=$ 272 volt

step in duty cycle creates a change of more than $1.1 \mathrm{~A}$ due to the high DC gain of the system.

\section{CONCLUSION}

This work has demonstrated the fractional charging for EV applications and the efficiency improvements in a fractional charging system, and given insight into modelling and control of such a system. It was found that the first order model presented is usable for controller design, but that it lacked information to describe the much slower rise time of the tested system. Furthermore, an optimization procedure for the design of a highly efficient DC-DC converter is explained.

\section{ACKNOWLEDGEMENT}

The authors would like to thank Lithium Balance A/S for their help and for lending out an electric vehicle for testing.

\section{REFERENCES}

[1] K. L. Jørgensen, M. C. Mira, Z. Zhang, M. A. Andersen et al., "Review of high efficiency bidirectional dc-dc topologies with high voltage gain," in Universities Power Engineering Conference (UPEC), 2017 52nd International, pp. 1-6. IEEE, 2017.

[2] R.-J. Wai, R.-Y. Duan, and K.-H. Jheng, "High-efficiency bidirectional dc-dc converter with high-voltage gain," IET Power Electronics, vol. 5 , no. 2, pp. 173-184, 2012.

[3] L. C. Mazza, D. S. Oliveira, F. L. Antunes, D. B. Alves, and J. J. Souza, "A soft switching bidirectional dc-dc converter with high frequency isolation," in Power Electronics Conference and 1st Southern Power Electronics Conference (COBEP/SPEC), 2015 IEEE 13th Brazilian, pp. 1-6. IEEE, 2015.

[4] M. Kwon, S. Oh, and S. Choi, "High gain soft-switching bidirectional dc-dc converter for eco-friendly vehicles," IEEE Transactions on Power Electronics, vol. 29, no. 4, pp. 1659-1666, 2014.

[5] H.-J. Chiu and L.-W. Lin, "A bidirectional dc-dc converter for fuel cell electric vehicle driving system," IEEE Transactions on Power Electronics, vol. 21, no. 4, pp. 950-958, 2006.

[6] J.-Y. Lee, Y.-S. Jeong, and B.-M. Han, "A two-stage isolated/bidirectional $\mathrm{dc} / \mathrm{dc}$ converter with current ripple reduction technique," IEEE Transactions on Industrial Electronics, vol. 59, no. 1, pp. 644-646, 2012.

[7] B. Li, Q. Li, F. C. Lee, Z. Liu, and Y. Yang, "A high efficiency high density wide-band-gap device based bi-directional on-board charger," IEEE Journal of Emerging and Selected Topics in Power Electronics, 2018. 
[8] S. Jeong, J.-M. Kwon, and B. Kwon, "High efficiency bridgeless singlepower-conversion battery charger for light electric vehicles," IEEE Transactions on Industrial Electronics, 2018.

[9] R. M. Button, "An advanced photovoltaic array regulator module," in Energy Conversion Engineering Conference, 1996. IECEC 96., Proceedings of the 31st Intersociety, vol. 1, pp. 519-524. IEEE, 1996.

[10] V. M. Iyer, S. Gulur, G. Gohil, and S. Bhattacharya, "Extreme fast charging station architecture for electric vehicles with partial power processing," in Applied Power Electronics Conference and Exposition (APEC), 2018 IEEE, pp. 659-665. IEEE, 2018.

[11] F. Xue, R. Yu, and A. Huang, "Fractional converter for high efficiency high power battery energy storage system," in Energy Conversion Congress and Exposition (ECCE), 2017 IEEE, pp. 5144-5150. IEEE, 2017.

[12] K. Tomas-Manez, A. Anthon, and Z. Zhang, "High efficiency power converter for a doubly-fed soec/sofc system," in 2016 IEEE Appl. Power Electron. Conf. Expo, pp. 1235-1242, 2016.
[13] K. Fahem, D. E. Chariag, and L. Sbita, "On-board bidirectional battery chargers topologies for plug-in hybrid electric vehicles," in Green Energy Conversion Systems (GECS), 2017 International Conference on, pp. 1-6. IEEE, 2017.

[14] K. Venkatachalam, C. R. Sullivan, T. Abdallah, and H. Tacca, "Accurate prediction of ferrite core loss with nonsinusoidal waveforms using only steinmetz parameters," in Computers in Power Electronics, 2002. Proceedings. 2002 IEEE Workshop on, pp. 36-41. IEEE, 2002.

[15] H. He, R. Xiong, and J. Fan, "Evaluation of lithium-ion battery equivalent circuit models for state of charge estimation by an experimental approach,” Energies, vol. 4, no. 4, pp. 582-598, 2011.

[16] R. W. Erickson and D. Maksimovic, Fundamentals of power electronics. Springer Science \& Business Media, 2007.

[17] A. Anthon, Z. Zhang, M. A. E. Andersen, D. G. Holmes, B. McGrath, and C. A. Teixeira, "The benefits of sic mosfets in a t-type inverter for grid-tie applications," in Transactions on Power Electronics, pp. 2814 2816. IEEE, 2017 